\title{
Effects of Demand Charging and Photovoltaics on the Grid
}

\author{
Simulation for Retail Electricity Customers
}

\author{
Yannic Domigall, Antonia Albani, Robert Winter \\ Institute of Information Management \\ University of St.Gallen \\ St.Gallen, Switzerland \\ [yannic.domigall, antonia.albani, robert.winter]@unisg.ch
}

\begin{abstract}
Due to the integration of renewable energies, the electricity grid is confronted with new peak situations that are caused by the new power plants. Beside these threats new metering technologies combined with information systems enable new pricing options that were not affordable for retail customers before. This paper contributes to the field by combining demand charging incentives with a feed in tariff for photovoltaics. Demand charges are a broadly used pricing concept for large scale and industrial customers but are not used for retail customers yet. In a simulation we first of all show the impact of solar plants on the grid. Secondly, we simulate the shift in electricity demand caused by a demand charge for retail customers. Our simulation shows that the solar panels reduce the purchased quantity of electricity while leaving the maximum peak unchanged. This leads to reduced revenues for grid operators without changing the costs. This negative impact can be improved by the demand charge for retail customers.
\end{abstract}

\section{Keywords—Demand Charge; Electricity Grid; Simmulation}

\section{INTRODUCTION}

The electricity industry is currently facing a massive change of its production capacity. Photovoltaics only account for about 7\% [1] of the produced electricity in Europe in 2012, but this percentage is rapidly increasing. According to [1] photovoltaic power plants make up $47 \%$ of the net new power capacity installed in Europe in 2012. At the electricity production side, more and more electricity is therefore cocreated by retail customers. The integration of the renewable sources into the grid will cause peak situations in the future and is therefore a potential threat for the grid stability [2]. Beside many technical solutions that prevent the grid from damage or black out, there are some behavior changing possibilities that lead to a more stable grid as well. The pricing of grid usage for customers is one possibility for such a measure that sets monetary incentives to coordinate the grid usage. Experiments and pilot studies as for example the critical peak pricing [3] and the interruptible and curtailable rate [4] show that new pricing options for retail customers may have significant impact on the electricity demand and therefore on grid stability. None of these works do however focus on demand charge for retail customers. This is exactly where our paper contributes to the field. Firstly, we present a simulation of the effects of a demand charge for retail customers on the electricity grid, and secondly we combine the demand charging approach with a feed-in-tariff for photovoltaics. The simulation builds a basis for the further evaluation of the demand charge for retail customers regarding its ability to contribute to grid stability. It furthermore demonstrates the free rider problem of solar plant owners that use the public grid as a backup power plant. The underlying assumption of our simulation is that a full roll out of smart meters makes sense in Switzerland [5] and that it will be started during the next years. The simulation we present in this paper is not only relevant for Switzerland but for many other European countries as well. The reason is that smart meters have been rolled out in several European countries during the last years or will be rolled out in the next years.

The idea of charging customers for the maximal peak they cause is not new at all. The demand charge reaches back to the beginning of the electrification and is therefore as old as the grid itself. The crucial point however is that the electricity industry is currently confronted with many new technical options within different steps of the value creation chain. The new developments in the electricity metering environment open up many new pricing possibilities for retail customers that were hitherto only available for commercial and industrial customers [6]. On one hand, demand charging was simply too expensive for retail customers. On the other hand, customers did not produce electricity on their own.

Another aspect that is gaining more importance is that scarce electricity transportation capacities should be utilized as cost efficient as possible by maximizing the parallelization of electricity production and consumption by residential consumers [7]. This issue is addressed by our tariff; Net peaks are reduced by consuming a bigger fraction of the produced electricity.

In this paper we simulate the impacts of demand charging on the daily load profile of retail customers. The individual load profiles are then aggregated into a combined load profile. We use daily load profiles since they are much easier to visualize than monthly load profiles. We show that the demand charge has a peak reducing impact on the aggregated load profile.

The structure of the paper is as follows. In the section Related Work existing prizing alternatives are discussed. The demand charge is presented in section Demand Charging for Retail Customers. A first simulation of the effects of demand charging and photovoltaic solar plants on the grid is presented in section Simulation of effects. In section Conclusions and Future Work we summarize and discuss our results and propose ideas for future research. 


\section{RELATED WORK}

Many papers consider single tariffs and their effect on a certain peer group [3]. Publications dealing with many different tariffs are rather rare. A good overview regarding demandresponse programs gives Faruqui $[6,8]$. The Federal Energy Regulatory Commission published in 2006 an assessment of demand response and advanced metering and revised it in 2008 [9]. The Swiss Federal Department UVEK published a smart metering study considering different tariffs and options for a smart meter rollout in Switzerland [10]. A German smart metering study that deals with tariffs was published in 2009 in cooperation with the Federal Network Agency [11]. There are several electricity tariffs currently used by utilities.

The tariffs are subdivided into clusters. Fix and variable tariffs are fundamentally different. Variable tariffs may furthermore be subdivided according to their dependent variables such as time, load or market price [9, 10]. This chapter provides an overview and a short description of the different pricing options.

The fix tariff (also called flat pricing) is probably the bestknown and most frequently used tariff. A fix tariff may either be fix per unit (e.g., kWh) or per time period (e.g., one year). It is often the standard or basic tariff and will therefore not be described in detail in this paper. For more information on fix tariffs we refer to [9]. Variable tariffs may depend on time, load or price as an independent variable and will be explained next.

The time-of-use tariff is time variable and consists of at least two different rates. Time of use pricing is frequently used by utilities [9]. It is often known as a low-load tariff / peak-load tariff [12]. Another example for a time variable tariff is the critical-peak pricing. Critical-peak pricing is not an everyday pricing model, but an overlay over a basic model. It is only used if extreme peaks are expected. Three facts are characteristic for the critical-peak pricing: It is restricted to a limited amount of hours per year, it is much higher priced than normal peak-load tariffs and it is very short term called for a previously unknown time period [3, 9]. The last broadly used tariff is the real-time pricing. The electricity prices in real-time pricing are the most flexible prices that are possible, since they may change within minutes. A utility can index the prices to an energy exchange or a scarcity situation in the grid. This enables a customer participation in market volatility and arbitrage options [9]. Aside from the time dependent tariffs, demand bidding is an option to link the pricing to market or grid requirements. If electricity suppliers may pass on the market prices to their customers, then we talk about a demand bidding treaty. In the past, this kind of demand response has especially been used for large customers [10]. Beside this time dependent tariffs and demand bidding, load dependent tariffs play a major role. Direct-load control is a basic form of demand side management. It enables the utility or system operator to remotely control electronic appliances on the customer side. A ripple control unit for example sends the control impulse. Direct-load control is often limited by the number of hours per day that a load may be cut off [10]. Curtailable load is another form of demand side management. Customers agree to reduce load in exchange for better pricing conditions. If customers do not reduce load during peak price conditions, a penalty payment is charged. Since this tariff requires customers to actively reduce their consumption, it is more suitable for large customers [4]. For customers with higher price sensitivity the interruptible load tariff may be a good choice. This enables the utility to disconnect consumer load from the grid. This tariff is broadly used e.g., for heat pumps.

Demand charge or maximum load is a load variable tariff that uses the utilized $\mathrm{kW}(\mathrm{kVA})$ as a basis instead of $\mathrm{kWh}$. Customers pay for the one single peak $(\mathrm{kW})$ they created during a specified time period or have a limited $\mathrm{kW}$ amount they may use [4]. We use this tariffing possibility in the simulation to understand its impact on retail customers. The demand charge has been used as early as at the beginning of the last century. Its original idea was to increase the competitiveness of utilities in the United States. This was necessary because the primary source of electricity for industry was self-generation and not the utilities [13]. The demand charge was probably a good prize discrimination option for utilities in the early days of the centralized production of electricity [13]. The use of a demand charge enabled the utility to differentiate between retail customers and customers with an isolated own plant. These customers were potential candidates for demand charging, if the customers operating costs exceeded the utilities marginal costs, but were below the normal market prizes the smaller customers were charged [13]. Today, the newly developed metering infrastructure enables demand charges for retail customers at affordable costs. Due to the structural change in the electricity production infrastructure, more and more customers are producers themselves and have therefore similar negotiation position as industrial customers had one century ago. However, beside all this similarities, there are two major differences between the situation today and one hundred years ago. Firstly, we assume that individual peaks are more likely to occur simultaneously with system peaks than industrial peaks were in the past according to [13]. If this assumption holds, a reduction of individual peaks should, at least to a certain extent, lead to a reduction of the system peak. Secondly, if the system peak is caused by the feed in of photovoltaic solar panels, the individual peaks are highly correlated with the system peak and the negative effects of a demand charge are therefore considered to be conceivably low.

TAB. I: TARIFFING OPTIONS COMPARED

\begin{tabular}{|c|c|c|c|c|}
\hline & 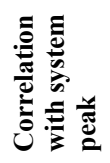 & 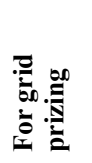 & 冚 & 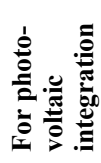 \\
\hline Fixed tariff & & $\mathrm{X}$ & & \\
\hline$\underset{\text { tariff }}{\text { Time-of-use }}$ & $\mathrm{X}$ & $\mathrm{X}$ & $\mathrm{X}$ & \\
\hline $\begin{array}{c}\text { Critical-peak } \\
\text { pricing }\end{array}$ & $\mathrm{X}$ & $\mathrm{X}$ & $\mathrm{X}$ & \\
\hline $\begin{array}{l}\text { Direct-load } \\
\text { control }\end{array}$ & $\mathrm{X}$ & & & $\mathrm{X}$ \\
\hline $\begin{array}{c}\text { Interruptible } \\
\text { / curtailable } \\
\text { load }\end{array}$ & $\mathrm{X}$ & & & $\mathrm{X}$ \\
\hline
\end{tabular}


Tab. I summarizes the relevant tariffing options known to the authors and mentioned above. It becomes evident that those models do not combine behavior modification with photovoltaic integration into a single tariffing option. This is exactly where this paper contributes to the field.

\section{LOADVARIABLE GRID PRICING}

The tariff that is simulated in this paper consists of a supply and a delivery part of electricity and includes a base fee. The supply part is a time of use tariff that uses two different prize levels for the delivered electric energy. The electricity used during the night and on weekends is approximately $50 \%$ cheaper than the electricity used during a working day. Since the considered customers are not only consuming, but also producing electricity, we have to look at the feed-in tariff as well. The feed-in tariff is the amount of money a customer gets for the utility of electricity that he produces on his own and feeds into the public grid. The compensation for this produced electricity is slightly below (about 5\%) the amount a customer would have paid for the import of the same quantity of electricity from the grid. The difference is so small since the customer is paid an extra fee for the ecological value of the solar power. The quantity of electricity a customer does not feed into the grid, but consumes on his own is designated as self-consumption. The utility does not impose a charge on this quantity. This seems trivial, but today Swiss solar panel owners that receive a federal compensatory feed-in remuneration, are not allowed to consume this electricity on their own. They pay therefore taxes on every kilowatt hour $(\mathrm{kWh})$ used - not only on the electricity purchased from the grid. This supply charging part of the electricity bill has already been implemented by our industry partner and is therefore included in the data for our simulation.

Fig. I presents a graphical overview of the variable tariff elements of the supply part of the tariff. The shaded bars in the bar chart represent the corresponding feed-in tariff. The Highrate tariff is used as a reference and is shown as $100 \%$.

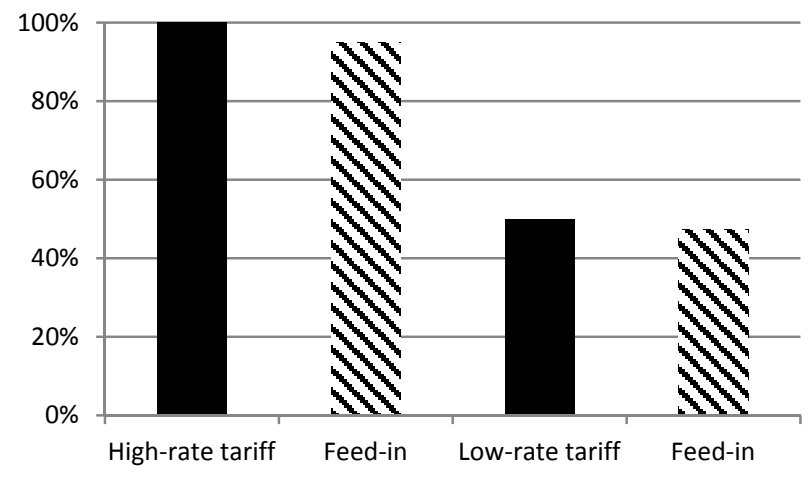

FIG. I: RETAIL TARIFFS AND FEED-IN TARIFFS COMPARED

Beside this the prizing of the used electricity in the supply part, the delivery part has to be prized as well. The amount payable often consists of a fix basic service charge and a variable amount that depends on the electricity used [14, 15]. We do not focus on the fix basic service charge here because it does not have a direct impact on the consumed quantity or the demand peak and is therefore not relevant for the simulation.
Instead we take a closer look at the variable part of the grid prizing. The variable grid prizing of retail customers was a pragmatic and fair grid cost distribution. The prizing was pragmatic because the meter infrastructure enabled this form of prizing and other meters were available but too expensive for retail customers. The prizing was also fair because electricity was produced in centralized power plants and then distributed to the customers. Today the prizing per $\mathrm{kWh}$ is not necessarily fair anymore because $\mathrm{kWh}$ prizing is only a pragmatic approximation to the real costs. The clients paid a specific amount to the utility in the past for every kWh they consumed. However for the dimensioning of the grid, the expected maximal load and not the number of transported $\mathrm{kWh}$ is the relevant factor. If retail clients purchase all $\mathrm{kWh}$ they consume via the public grid, the quantity of $\mathrm{kWh}$ used reflects their grid usage quite good. For consumers that own a solar panel, the maximum grid usage in watts probably stays the same, but the quantity of $\mathrm{kWh}$ purchased via the grid decreases. This leads to reduced revenues of the utility for grid usage, even though the same infrastructure is necessary as before. A possible impact on a reduced average load with the same maximal load is shown in Fig. II.

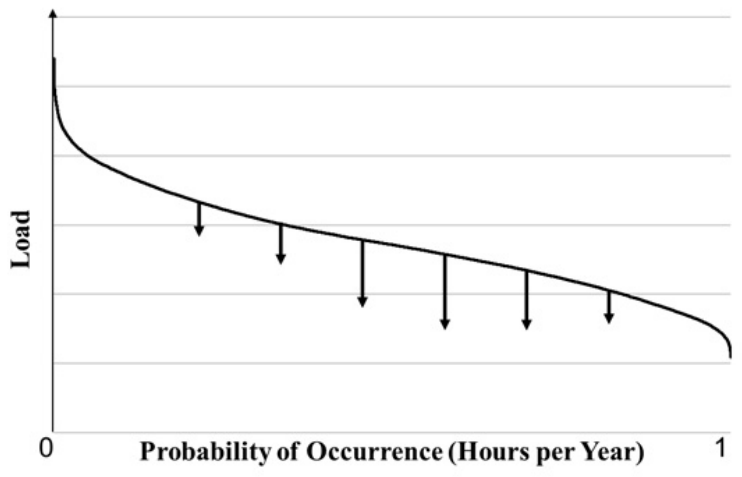

FIG. II: LOAD SORTED BY OCCURRENCE PROBABILITY

The solid line is the actual situation; the arrows represent a possible shift of this curve as a result of a reduced electricity purchase from the grid. In the scenario that we present in the next section, we assume that solar panels are installed and the maximum load stays the same. The grid is prized per $\mathrm{kWh}$ $(0.001 \mathrm{MWh})$ in the status quo scenario. In Fig. II the area below the curve represents the integrated load per time reflecting the revenues generated by this specific grid. It is obviously that the shift, which represents the impact of the extra photovoltaic panels, reduces the area under the probability curve and, as a consequence, reduces the revenues for grid maintenance. "Enthusiasts have named the symbolic milestone when the cost of solar energy becomes competitive with conventional grid supplied electricity - grid parity" [16]. This symbolic moment of parity between residential production costs and prizes per $\mathrm{kWh}$ from the grid, sets economic incentives to the utility's customers and is therefore relevant for the prizing of the delivery part. If customers pay the grid per $\mathrm{kWh}$, grid parity is much faster reached even if the maximal usage in $\mathrm{kW}$ does not change. If grid parity has been reached to sufficiently fund the grids, new grid prizing options are necessary to reduce this negative incentive to free ride and to use the grid as a cheap back up. 


\section{SimUlation OF EFFECTS}

In this section we first of all simulate the impact of additional solar panels on the grid presented in Fig. II. This simulation is the basis for our argumentation for the need of new grid prizing models. Secondly we simulate the impact of such a model, namely the demand charge, on day load curves of retail clients.

The load of a distribution grid in Switzerland in quarters of hours looks like the graph of the dotted line in Fig. III.

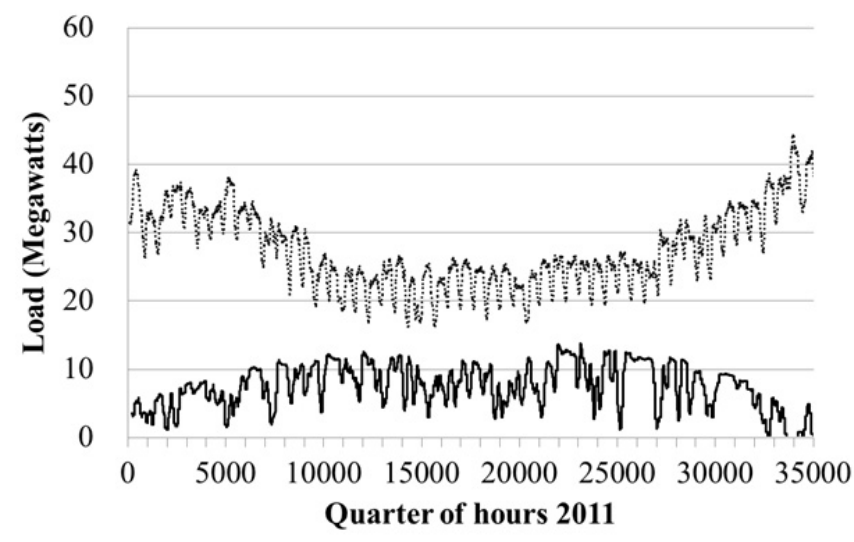

FIG. III: LOAD OF A GRID AND PHOTOVOLTAIC PRODUCTION

The electricity production of photovoltaic panels (solid line) is highly dependent on weather conditions and the ecliptic. For simplicity reasons we assume in this scenario, that small solar panels are installed and the total production is directly consumed or stored in an accumulator and consumed during the next two days. This is also the reason, why we do not assume, that negative grid loads in our simulation are possible. Both curves shown in Fig. III are visualized by using the moving average of 192 quarters of an hour, which is two days. This leads to a good visualization of the general trend of the graph. The amount of installed solar power in this scenario is 45 megawatts of solar peak load compared to the status quo of the grid. The baseline is shown as a dotted line in Fig. III and Fig. IV. The solid line represents the simulated load after the additional solar panels have been installed. In Fig. IV we have sorted the load according to its probability of occurrence.

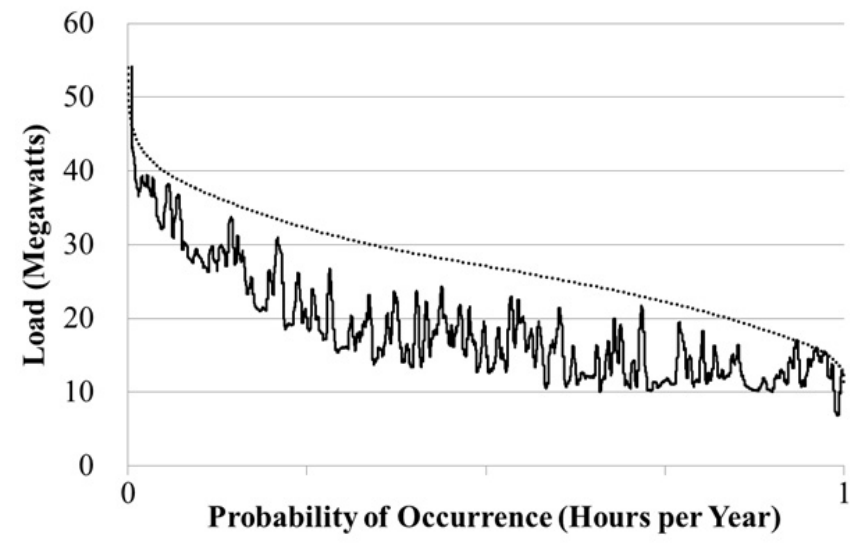

FIG. IV: LOAD IMPACT OF PHOTOVOLTAIC SOLAR PLANTS
Sorting the load and production data of the simulated photovoltaic modules according to their occurrence probability (as shown in Fig. IV) helps us understanding how often and when a solar induced load reduction take place. The ideal degree of capacity utilization from a grid operator's perspective is a straight line that lies near the theoretical transportation maximum. Every deviation from this ideal quantity implies a reduction in the revenues a grid operator has if payments correspond to the quantity of transported units. The status quo of the grid utilization is far away of the ideal line e.g., at 55 megawatts in Fig. IV. This is a normal situation because the quantity of the consumed electricity depends highly on outdoor temperature, season and day of the week. Nevertheless, the photovoltaic plants as shown by the moving average in Fig. IV lead to a further reduction of the load in the middle area of the graph, while the extreme values stay exactly the same. The revenues of the grid operator are therefore smaller, while the maximum load stays equal. This effect could be corrected when a different pricing system is used, that uses the maximum load and not the used quantity as a basis.

In the following section we simulate a possible impact of the demand charge tariff on the grid peak. We are aware that this tariff reduces the individual's peaks and not necessarily the global peaks of the grid. We assume however, that the peaks are often correlated and the tariff is therefore useful.

The data that we use for our simulation have been measured by smart meters and represent the average load in $\mathrm{kW}$ of 15 min. intervals. The meter saves 96 values for each day and 35040 values per year. These values can be used to identify the individual's peak load. In our simulation we use aggregated meter data of ten customer's day load curves. The main advantage of the use of day load data is the good visualization ability compared to a monthly or yearly visualization. Fig. V shows a principle depiction of a customer's day load profile. In this case the customer used a lot of electricity between 11:00 and 13:00, maybe by cooking and washing at the same time. In the morning the consumed quantity was small. The smaller peaks throughout the day are caused by a refrigerator or another heat pump that was running during the whole day.

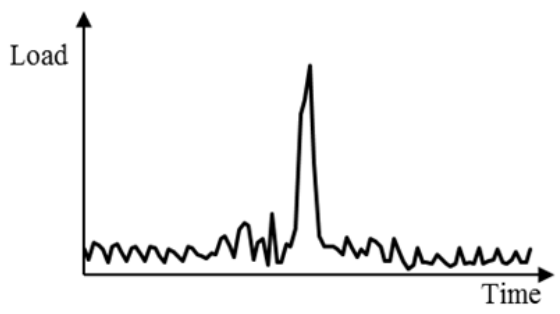

FIG. V: EXTREME DAY LOAD PROFILE

For our simulation we assume that the customers try to allocate their use of electricity. We calculate the average over a specific peak including the preceding and the subsequent quarter of an hour by using (1). A peak is defined in this case as the biggest five values of a day load profile of a specific customer $(n=5)$.

$$
M=\frac{1}{n} \sum_{i=1}^{n} x_{i}
$$


An exemplary smoothing of the peak data is shown in Figure VI. The maximum peak load of $5.22 \mathrm{~kW}$ was reduced by about $2.32 \mathrm{~kW}$ to the average of $2.9 \mathrm{~kW}$ load. This leaves the total amount of electricity used unchanged.

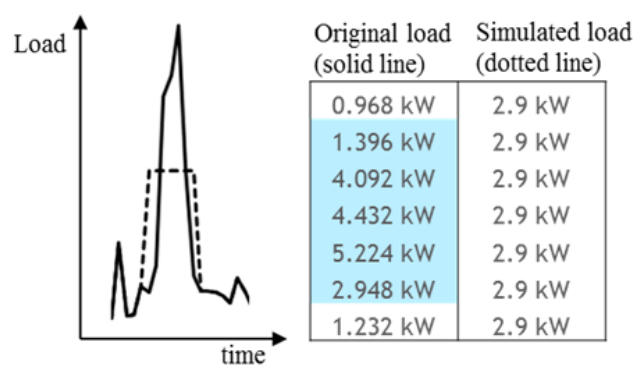

FIGURE VI: SMOOTHING OF PEAK LOAD

The five dyed cells in Figure VI represent the biggest five values in the day load profile of a specific customer at a given day. The second column shows the values after the smoothing. These values were calculated by using (1) and leave the consumed quantity of electricity that equals the area below each curve unaltered. The solid line in Figure VI represents the original load curve as measured by a smart meter, while the dashed line stands for the smoothed data of our simulation. We are aware that the load shift of customers may look very different from our assumption, but avoiding the parallel operation of devices as dishwasher, oven, washing machine, tumble dryer and electric heating as the main electricity consumers, should enable similar shifts [17]. As mentioned in the introduction, the parallelization of production and consumption of electricity is gaining more and more importance. This issue is addressed by our tariff as well having net peaks only measured in case a customer produces electricity with a solar panel. The tariff sets therefore two incentives to stabilize the grid. First, by reducing possible peaks in the future that would be caused by solar panels. Second, by reducing the demand peaks of every individual and thereby contributing to the reduction of the general peak in the grid. In Figure VII we show the relation of the day load profile presented in Fig. $V$ with a typical solar production measured in the same time period.

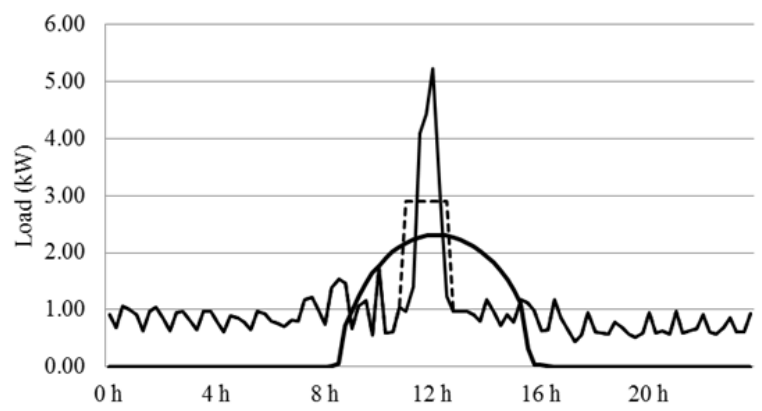

FIGURE VII: OVERLAY OF DEMAND AND SOLAR PRODUCTION

The dashed line represents the data after the reduced peak demand, as a reaction to the demand charge explained in Fig. I. The central goal of our simulation was however not the reduction of an individual's peaks, but instead the reduction of the grids peaks. To simulate the effects of the demand charge, we use smart meter data of day load profiles. The aggregated load may then be analyzed in order to understand the tariff's impacts. In Figure VIII the aggregated load curve is shown.

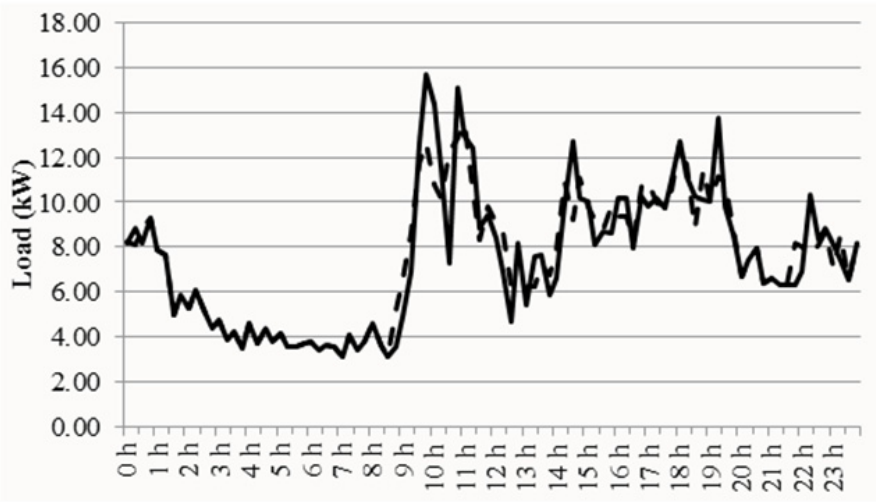

FIGURE VIII: IMPACT OF DEMAND CHARGING

The solid line in Figure VIII represents the original load curve as measured by the smart meters, while the dashed line shows the impact of a potential demand charge that leads to a reduced aggregated peak. The main peak is obviously reduced, but it is difficult to quantify the total impact based on Figure VIII. Therefore we again use a probability graph (Figure IX) for visualizing the results. The load values are sorted by their occurrence probability from 0 (origin of the coordinate system) to 1 (right hand side).

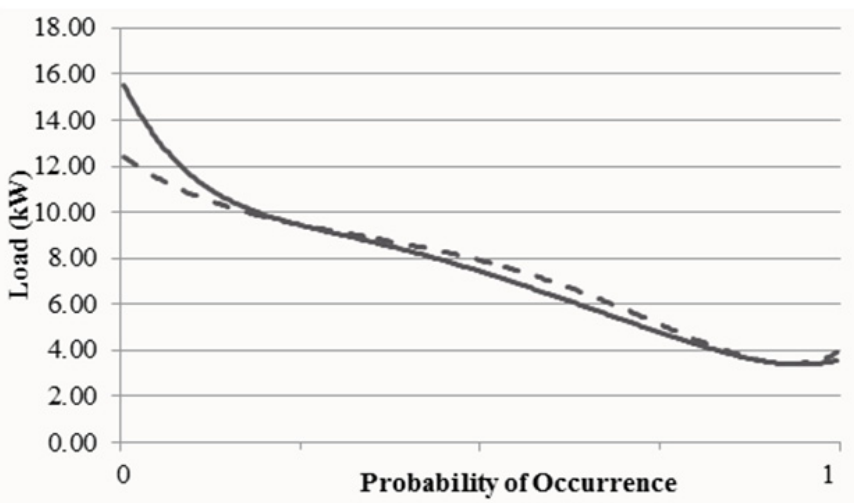

FIGURE IX: IMPACT SORTED BY PROBABILITY OF OCCURRENCE

In Figure IX, the dashed line represents the simulated scenario and the solid line the original load curve as in Figure VIII. The peak reduction is again clearly visible. The load has been shifted to the middle load area. The demand charge scenario has hardly affected the load in the low load area. Even though, the demand charge is referenced, as a misinterpretation of the peak pricing concept [13], the effect in this simulation case is positive. 


\section{CONCLUSION AND FUTURE WORK}

Due to technical innovations in the field of metering appliances, new pricing options for retail customers will become possible in the next years. The booming integration of renewable electricity sources, especially photovoltaic power plants, imply changes in the grid pricing structure in order to prevent the misuse of the public grid as a backup facility. This paper is a first step in that direction by simulating possible impacts of a demand charge tariff that uses the electricity load as a basis for the grid pricing instead of the used quantity of energy. The paper's contribution is twofold: Firstly, awareness is created for the free-rider phenomenon of solar panel operators if grid parity is reached. Secondly, a grid prizing option is proposed that was not available in the past due to technical restrictions of the metering infrastructure. The simulation results can be used for the grid optimization in countries, with similar load profiles to Switzerland. The results are especially not valid for regions with a high correlation of consumption peak and sunshine intensity. Such a correlation may for example be caused by air conditioners. Another aspect that may differ between the countries is the willingness of the consumers to shift load and the willingness of the utilities to pay an extra amount for the ecological value of solar power.

We are aware that our simulation faces several limitations. First of all, we use the moving average instead of the original smart meter data, to visualize the consumed quantity of electricity. Due to the relatively small number of simulated day load profiles we use, the results are not necessarily representative for all retail customers. The further understanding of the interdependencies between the electricity demand peaks of individuals and the global grid peak is subject to our current research. For the future, our aim is to simulate the load profiles by using monthly (instead of daily) load profiles. This simulation should then show how the tariff reduces the grids load when using different customers load profiles.

We plan to implement the tariff together with an energy provider in Switzerland in form of a pilot project. In a first step, 10 - 50 retail customers with own solar panels and willing to test the newly developed tariff will be selected . In a second step, we will evaluate the data of the pilot project some month after the implementation in order to understand the impact of the tariff.

\section{REFERENCES}

[1] Ewea. (2013, 10.04.2013). Wind in power 2012 European statistics. Available: http://www.ewea.org/fileadmin/files/library/publications/ statistics/Wind_in_power_annual_statistics_2012.pdf

[2] E. Troester, "PV self-consumption optimization with storage and Active DSM for the residential sector," 2009, pp. 9-10.

[3] K. Herter, "Residential implementation of critical-peak pricing of electricity," Energy Policy, vol. 35, pp. 21212130, 2007.

[4] D. Caves, et al., "Load impact of interruptible and curtailable rate programs: evidence from ten utilities [tariff incentives]," IEEE Transactions on Power Systems, vol. 3, pp. 1757-1763, 1988.

[5] M. Baeriswyl, et al. (2012, 10.04.2013). Folgeabschätzung einer Einführung von «Smart Metering» im Zusammenhang mit «Smart Grids» in der Schweiz. Available:

http://www.news.admin.ch/NSBSubscriber/message/atta chments/27519.pdf

[6] A. Faruqui, et al., "Unlocking the $€ 53$ billion savings from smart meters in the EU: How increasing the adoption of dynamic tariffs could make or break the EU's smart grid investment," Energy Policy, vol. 38, pp. 62226231, 2010.

[7] M. Castillo-Cagigala, et al., "PV self-consumption optimization with storage and Active DSM for the residential sector," Solar Energy, vol. 85, pp. 2338-2348, 2011.

[8] A. Faruqui, et al., "Piloting the Smart Grid," The Electricity Journal, vol. 22, pp. 55-69, 2009.

[9] C. Federal Energy Regulatory. (2006) Assessment of Demand Response \& Advanced Metering. Washington D.C.

[10] R. Dettli, et al. (2009, 23.04.2012). Smart Metering für die Schweiz - Potenziale, Erfolgsfaktoren und Massnahmen für die Steigerung der Energieeffizienz. Available:http://www.bfe.admin.ch/04266/index.html?la ng=de\&dossier_id $=04264$

[11] Bundesnetzagentur. (2009, 25.04.2012). Wettbewerbliche Entwicklungen und Handlungsoptionen im Bereich Zählund Messwesen und bei variablen Tarifen. Available: http://www.bundesnetzagentur.de/SharedDocs/Download s/DE/BNetzA/Sachgebiete/Energie/Sonderthemen/Berich tZaehlMesswesen/BerichtZaehlMesswesenpdf.pdf?_blo $\mathrm{b}=$ publicationFile

[12] C. Aichele, "Dynamische Tarife zur Kundeninteraktion mit einem Smart Grid," in Smart Energy, C. Aichele, Ed., ed Wiesbaden: Vieweg+Teubner Verlag, 2012, pp. 229-258.

[13] J. L. Neufeld, "Price Discrimination and the Adoption of the Electricity Demand Charge," The Journal of Economic History, vol. 47, pp. 693-709, 1987.

[14] ConEdison. (2013, 17.04.2013). Interactive model of a residential or small non-residential bill. Available: http://www.coned.com/customercentral/threebill_D19_R esDual.asp

[15] B. F. E. AG. (2013, 18.04.2013). Simulierte Rechnung. Available:

http://bkw.1tolenergy.ch/etc/medialib/partnersites/bkw_f mb/downloads/services.Par.93150.File.pdf

[16] C.-J. Yang, "Reconsidering solar grid parity," Energy Policy, vol. 38, pp. 3270-3273, 2010.

[17] G. Wood and M. Newborough, "Dynamic energyconsumption indicators for domestic appliances: environment, behaviour and design," Energy and Buildings, vol. 35, pp. 821-841, 2003. 